\title{
Sensitivity of elastic thickness to water in the Martian lithosphere
}

\author{
Ikuo Katayama ${ }^{1 *}$ (D), Yuhki Matsuoka ${ }^{1}$ and Shintaro Azuma ${ }^{2}$
}

\begin{abstract}
Ancient Mars likely hosted oceans similar to those on Earth; however, such water is not presently observed on Mars. One possible explanation for the lack of present-day oceans is that surface water was transported into and stored within the interior of Mars throughout the geological history. As water can influence the rheological structure of the Martian lithosphere, we investigated the sensitivity of the elastic thickness of the lithosphere to water using recent laboratory data. Calculations indicate that the presence of water results in a significant decrease in elastic thickness relative to dry conditions at a given thermal structure. Gravity and topographic data acquired by the Mars Global Surveyor and other orbiters indicate a temporal change in elastic thickness during the geological history of Mars. The extremely thin elastic layer during the planet's early history can be explained by a water-rich rheological model, whereas a dry rheology can account for the relatively thick elastic layer inferred during the later evolution of Mars. Although thermal evolution of Mars has a large uncertainty, the strong sensitivity of elastic lithospheric thickness to water suggests possible sequestered water into deeper levels during the early history of Mars.
\end{abstract}

Keywords: Rheological structure, Elastic thickness, Water, Mars

\section{Introduction}

Early Mars seemed to have a significant amount of water that would have covered a hypothetically smooth planetary surface to depths of several hundred meters (e.g., Carr 1986; Baker et al. 1991). However, such water has since disappeared and the present atmosphere on Mars is highly dry (e.g., Barlow 2008). In contrast, oceans and a water-rich atmosphere have persisted throughout Earth's geological history. Therefore, a key question remains regarding how the paleo-ocean on Mars was lost and where the water was transported to. Water may have escaped to space due the relatively small gravitational energy on Mars, as indicated by an enrichment of deuterium in the present-day Martian atmosphere (Villanueva et al. 2015). However, these estimates cannot fully account for the initial water concentration inferred from fluvial and ponded features on Mars (e.g., Carr and Head 2003; Di Achille and Hynek 2010). Clay minerals produced through water-rock interaction are widespread in the relatively old terrains of Mars, and

\footnotetext{
* Correspondence: katayama@hiroshima-u.ac.jp

${ }^{1}$ Department of Earth and Planetary Systems Science, Hiroshima University,

Higashi-Hiroshima 739-8526, Japan

Full list of author information is available at the end of the article
}

geochemical tracers in Martian meteorites suggest a possible subsurface water reservoir (Ehlmann et al. 2011; Usui et al. 2015). However, such evidence is limited to the shallow crust, and it remains unclear whether water reservoirs exist deep within the interior of Mars.

Gravity and topography data from the Mars Global Surveyor and other orbiters indicate regional variations in the elastic thickness of the Martian lithosphere, where early formed terrains (Noachian, ca. > 3.7 Ga) are characterized by a thin elastic layer, whereas during the Hesperian to Amazonian the elastic layer was relatively thick (McGovern et al. 2002). This trend is generally controlled by lithosphere cooling over time but may also be influenced by the presence of water, as the elastic layer is controlled by rheological structure, which is critically dependent on water (e.g., Karato and Jung 2003; Hirth and Kohlstedt 2003).

Previous modeling have calculated elastic thickness from the rheological profiles in the Martian lithosphere (Ruiz et al. 2006; Grott and Breuer 2008; Thiriet et al. 2018); however, these studies have assumed a commonly used power-law creep, which is not adequate for lowtemperature plasticity. In the regions close to the brittleductile transition, Peierls creep becomes a dominant 
mechanism and makes a large contribution to estimate of elastic thickness (Fig. 1). Azuma and Katayama (2017) applied the Peierls creep to model the rheological structure of the Martian lithosphere; however, they focused on the transition from brittle to ductile deformation and did not estimate the elastic thickness. Solomon and Head (1990) calculated the elastic thickness while considering Peierls creep, although their calculations were limited to dry conditions. In addition, brittle strength can be reduced by the presence of clay minerals, as these minerals exhibited a markedly low frictional coefficient at wet environments (e.g., Morrow et al. 2000; Katayama et al. 2015). In this study, we use recent rheological data including Peierls creep and low frictional coefficient to investigate the sensitivity of elastic thickness to water, and test whether the regional variation of elastic thickness can be explained by presence or absence of water in the Martian lithosphere.

\section{Methods/Experimental}

Effective elastic thickness is a measure of the total strength of the lithosphere, which integrates contributions from both brittle and ductile layers, with moments balanced between those generated by tensional and compressional stress states in the lithosphere (Goetze and Evans 1979; McNutt 1984). In a lithosphere strength profile, brittle strength is controlled by frictional sliding and ductile strength is controlled by flow laws deduced from experimental results (Fig. 1). Owing to the temperature sensitivity of ductile deformation, the elastic thickness is often used to infer the thermal structure of the lithosphere (Solomon and Head 1990;
Zuber et al. 2000). However, in addition to temperature, mechanical strength and hence elastic thickness are also dependent on the presence of water. Under brittle conditions, increasing pore fluid pressure affects the frictional resistance of rocks, and frictional coefficient is influenced by the presence of clay minerals. During plastic deformation, the presence of intracrystalline water is known to reduce the flow strength by enhancing defect mobility. For this reason, elastic thickness can be highly sensitive to the presence and distribution of water in the lithosphere.

\section{Rheological structures}

In regions undergoing brittle deformation, the mechanical strength of a material is determined by the resistance to frictional sliding. The shear stress at which frictional sliding begins is dependent on the normal stress $\left(\sigma_{n}\right)$ applied on the frictional surface as follows:

$$
\tau=\mu \sigma_{n}+C
$$

where $\mu$ is the frictional coefficient and $C$ is the frictional cohesive strength. Frictional coefficients are similar for most investigated minerals $(\mu=0.6-0.85$; Byerlee 1978); however, recent laboratory data have shown that several clay minerals yield much lower coefficients $(\mu \sim 0.1$; Morrow et al. 2000; Tetsuka et al. 2018). In the present study, we used Byerlee's law to calculate the mechanical strength in the regions undergoing brittle deformation, but we also discuss the effect of clay minerals that reduce brittle strength at wet environment. The above relationship between shear and normal stress was rewritten in terms of maximum and minimum
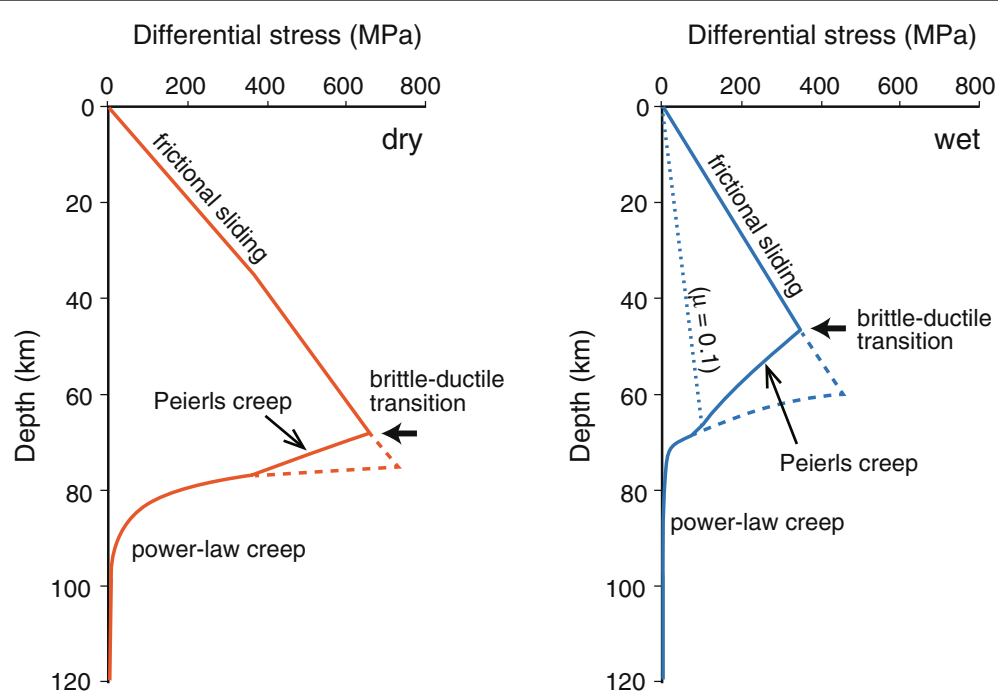

Fig. 1 Strength profile of the lithosphere under dry and wet conditions, calculated using a constant thermal gradient of $8 \mathrm{~K} / \mathrm{km}$ and strain-rate of $10^{-19} \mathrm{~s}^{-1}$. At shallow depths, deformation is mainly accommodated by frictional sliding, and at greater depths, deformation is accommodated by plastic deformation. Peierls creep becomes dominant at depth close to the brittle-ductile transition, resulting in a thinner elastic thickness than that calculated using power-law creep 
principal stresses in order to unify the coordination that used in the plastic deformation, assuming a fault oriented at $30^{\circ}$ from the axis of maximum compression. This approach is commonly used to calculate the strength envelope of the Earth (e.g., Kohlstedt et al. 1995). In compressional stress states, lithostatic pressure corresponds to the minimum principal stress, whereas under the tensional stress state, it is equivalent to the maximum principal stress. When pore fluid is present on the fault plane, the pore fluid pressure $\left(P_{\mathrm{p}}\right)$ reduces the effective normal stress $\left(\sigma_{n}^{\text {eff }}\right)$ as follows:

$$
\sigma_{n}^{\mathrm{eff}}=\sigma_{n}-\alpha P_{p}
$$

where $\alpha$ is close to 1 (Gueguen and Palciauskas 1994). This relationship indicates that frictional strength decreases in the presence of pore fluids. During modeling under wet conditions, the pore fluid pressure is assumed to be hydrostatic and was calculated using a water density of $1000 \mathrm{~kg} / \mathrm{m}^{3}$. Although clay minerals may not be widespread in lithosphere, a long-term fluid-rock interaction can generate weak materials such as talc (e.g., Hirauchi et al. 2016). Therefore, we also calculated brittle strength as an extreme case of wet conditions using a low frictional coefficient $(\mu=0.1)$.

In regions of plastic deformation, the mechanical strength was calculated using experimentally derived flow laws. A commonly used flow law is the power-law relationship between strain-rate $\left({ }^{\prime} \varepsilon\right)$ and stress $(\sigma)$, given by:

$$
\dot{\varepsilon}=A \frac{\sigma^{n}}{d^{m}} \exp \left(-\frac{E+P V}{R T}\right)
$$

where $A$ is a pre-exponential factor, $d$ is grain-size, $E$ is activation energy, $V$ is activation volume, $P$ is pressure, $T$ is temperature, and $R$ is the gas constant (Karato and Jung 2003; Hirth and Kohlstedt 2003). In this formula, $n$ and $m$ are constant exponents for stress and grain-size, respectively. Plastic strength is generally controlled by the weakest constituent mineral; consequently, we used plagioclase and olivine to calculate plastic strength for crust and mantle, respectively (e.g., Bürgmann and Dresen 2008). The parameters of flow laws are listed in Table 3. During diffusion creep, stress and grain-size exponents are 1 and 3 , respectively, whereas dislocation creep is insensitive to grain-size and has a stress exponent of $\sim 3$. Although such a formulation is frequently used to calculated plastic strength, limitations of the power-law formula have been reported at low temperatures and high stresses (Tsenn and Carter 1987), where it breaks down and the strain-rate becomes exponentially dependent on stress according to

$$
\dot{\varepsilon}=A \sigma^{2} \exp \left(-\frac{E+P V}{R T}\left(1-\frac{\sigma}{\sigma_{p}}\right)^{2}\right)
$$

where $\sigma_{p}$ is the Peierls stress (Katayama and Karato 2008). This mechanism, known as Peierls creep, becomes dominant around the depth of the brittle-ductile transition (Fig. 1). In our rheological model, we calculated plastic strength using a strain rate of either $10^{-16} \mathrm{~s}^{-1}$ or $10^{-19} \mathrm{~s}^{-1}$. This range of strain rates is consistent with geophysical observations of the Martian lithosphere (Schultz 2003), and a similar value was used during modeling by Solomon and Head (1990) and Ruiz et al. (2006).

Water enhances the rate of plastic deformation via an increase in defect mobility within crystals (e.g., Karato and Jung 2003; Hirth and Kohlstedt 2003). The influence of water depends on the chemistry of point defects, which varies among crystals and creep mechanisms. Since adequate experimental data are not available for each deformation mechanism, particularly for Peierls creep, we calculated the rheological structures using two end-member parameters, representing dry and wet conditions. Wet conditions were modeled using water contents of $\sim 10000 \mathrm{ppm} \mathrm{H} / \mathrm{Si}$ for plagioclase and $\sim 1000 \mathrm{ppm} \mathrm{H/Si}$ for olivine, corresponding to near-water saturated conditions at the depth of Moho (crust-mantle boundary).

\section{Calculation of elastic thickness}

Based on the strength profiles, we calculated the elastic thickness for the Martian lithosphere following the procedure described by McNutt (1984). In this model, the moment is calculated through a balance between tensional and compressional forces within a vertical cross section of the flexed lithosphere (Fig. 2). The integrated bending moment of the lithosphere is estimated by

$$
M=\int_{0}^{T_{m}} \sigma(z)\left(z-z_{n}\right) d z
$$

where $T_{\mathrm{m}}$ is the mechanical thickness of the lithosphere, $\sigma(z)$ is the strength at depth $z$, and $z_{\mathrm{n}}$ is the depth of the neutral stress plane. The mechanical thickness is controlled by the rheological boundary at the base of lithosphere, which is assumed to be the depth at which stress is < $50 \mathrm{MPa}$ (McNutt 1984; Solomon and Head 1990). The bending moment of the lithosphere is equivalent to that of the elastic core, as follows:

$$
M=\frac{E K T_{e}^{3}}{12\left(1-v^{2}\right)},
$$

where $E$ is Young's modulus, $K$ is flexural curvature, $v$ is Poisson's ratio, and $T_{\mathrm{e}}$ is the effective thickness of the elastic layer. The elastic constants of the lithosphere were assumed to be $E=100 \mathrm{GPa}$ and $v=0.25$, which are the same values as used during previous 


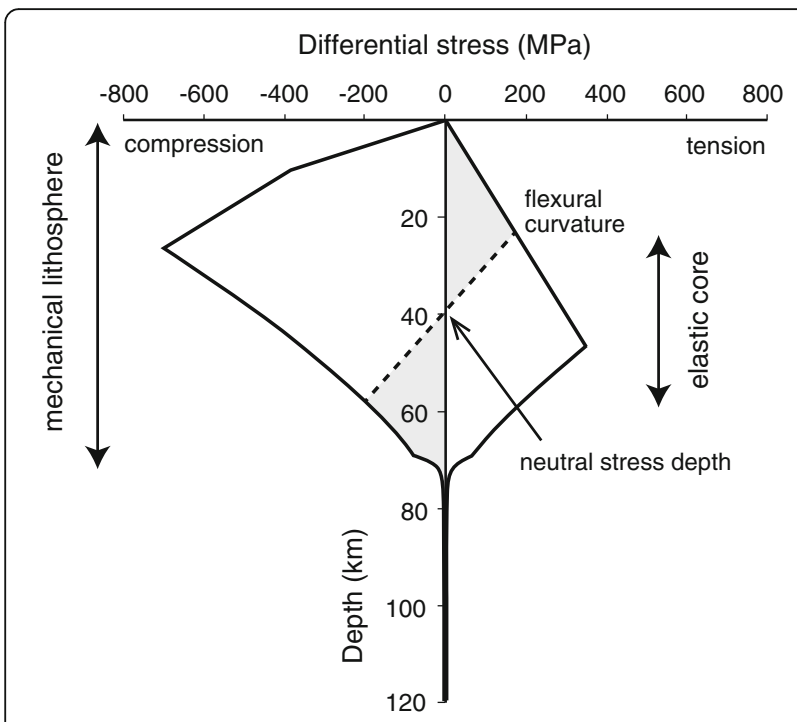

Fig. 2 Rheological model of the Martian lithosphere under wet conditions. A constant thermal gradient of $8 \mathrm{~K} / \mathrm{km}$ and a strain-rate of $10^{-19} \mathrm{~s}^{-1}$ were used in the calculations. Positive and negative differential stresses correspond to tension and compression, respectively. The bending moment is calculated via a balance between tensional and compressional forces within the flexed lithosphere (shaded area). Elastic thickness was calculated from the integrated bending moment following the procedure of McNutt (1984). Mechanical thickness is the rheological boundary at based of lithosphere, which is calculated from the depth where stress threshold is assumed to be $50 \mathrm{MPa}$ (McNutt 1984)

modeling (Ruiz et al. 2006). The estimate of elastic thickness depends on flexural curvature, and we used regional variations in curvatures calculated using a lithospheric deflection model (McGovern et al. 2004).

\section{Thermal modeling}

To assess the influence of water on elastic thickness, temperature must be modeled independently during the formation of elastic layers. Although dynamic modeling has been conducted to investigate the thermal structures of Mars (Guest and Smrekar 2007; Plesa et al. 2016), such an approach is highly dependent on mantle viscosity and is therefore sensitive to water. For this reason, we calculated thermal structure based on the chemical stratification and decay of radiogenic elements (e.g., Nimmo and Tanaka 2005), which is independent of water content. In our model, one-dimensional heat conduction equations were used to calculate temperature profiles on Mars, accounting for spatial variations in radioactive elements, crustal thickness, and geological age. According to Turcotte and Schubert (2002), temperatures in the crust $(T \mathrm{c})$ and mantle $(T \mathrm{~m})$ at depth, $z$, are given by:

$$
\begin{aligned}
& T_{c}=T_{0}+\frac{q_{0}}{k_{c}} z-\frac{\rho_{c} H_{c}}{2 k_{c}} z^{2} \\
& T_{m}=T_{\text {Moho }}+\frac{q_{m}}{k_{m}}\left(z-z_{\text {Moho }}\right)
\end{aligned}
$$

where $q_{0}$ and $q_{m}$ are the surface and mantle heat flows, respectively; $H_{c}$ is the radioactive heat production in the crust; $\rho_{c}$ is the density of the crust; $T_{0}$ and $T_{M o h o}$ are the temperature at the surface and Moho, respectively; $k_{c}$ and $k_{m}$ are the thermal conductivities of the crust and mantle, respectively; and $z_{M o h o}$ is the depth of the Moho. Parameters used in the calculations are listed in Table 1. The present-day heat production $H_{c}$ of 13 distinct geological locations in Mars was estimated from the local concentration of radioactive elements inferred from gamma-ray spectrometry data (Taylor et al. 2006) and crustal thicknesses (Neumann et al. 2004), which are listed in Table 2. In our model, we assumed that radioactive elements are concentrated in the crust and that heat from radioactive decay contributes to approximately half of the total heat flux based on the planetary differentiation model (Taylor et al. 2006). Estimates for present-day surface heat fluxes range from 8 to $18 \mathrm{~mW} /$ $\mathrm{m}^{2}$, nearly consistent with previous modeling (Laul et al. 1986; Treiman et al. 1986; Montesi and Zuber 2003; Nimmo and Tanaka 2005). To constrain heat production in the past, concentrations of individual radioactive elements were calculated using isotopic ratios and the halflife of each element (Turcotte and Schubert 2002). This model predicts an increase in surface heat flux during the early history of Mars (Fig. 3). The thermal models were then used to infer changes in the internal thermal structure of Mars, through correlation with the age of each location. Calculated thermal structures for Pavonis Mons, Alba Patera, and NE Arabia Terra are shown in Fig. 4.

Table 1 Physical and thermal parameters used in calculations

Crustal density $\left(\mathrm{kg} / \mathrm{m}^{3}\right) \quad 2900^{2}$

Crustal thermal conductivity $(\mathrm{W} / \mathrm{m} / \mathrm{K}) \quad 2.5^{\mathrm{b}}$

Mantle density $\left(\mathrm{kg} / \mathrm{m}^{3}\right) \quad 3500^{\mathrm{a}}$

Mantle thermal conductivity $(\mathrm{W} / \mathrm{m} / \mathrm{K}) \quad 3.2^{c}$

Surface temperature $(K) \quad 220^{d}$

Th/U ratio $\quad 3.8^{\mathrm{e}}$

Martian radius $(\mathrm{km}) \quad 3390^{\mathrm{a}}$

Surface gravity $\left(\mathrm{m} / \mathrm{s}^{2}\right) \quad 3.71^{\text {a }}$

Young's modulus (GPa) $100^{\mathrm{f}}$

Poisson's ratio

auber et al. (2000)

${ }^{\text {bClark (1966) }}$

'Nimmo and Stevenson (2000)

${ }^{d}$ Kieffer et al. (1977)

'Turcotte and Schubert (2002)

${ }^{f}$ McGovern et al. (2002) 
Table 2 Local variation in crustal structure and results of calculated elastic thickness

\begin{tabular}{|c|c|c|c|c|c|c|c|c|}
\hline Area & Age & $\begin{array}{l}\text { Crust thickness } \\
(\mathrm{km})\end{array}$ & $\begin{array}{l}\text { Curvature } \\
\left(10^{-7)}\right.\end{array}$ & Th (ppm) & K (ppm) & $\begin{array}{l}\text { Elastic thickness } \\
(\mathrm{km}) \text { dry model }\end{array}$ & $\begin{array}{l}\text { Elastic thickness } \\
(\mathrm{km}) \text { wet model }\end{array}$ & $\begin{array}{l}\text { Elastic thickness } \\
(\mathrm{km}) \text { wet clay model }\end{array}$ \\
\hline Olympus Mons & Amazonian & 55 & 1.6 & 3390 & 0.63 & $129-155$ & $22-30$ & $17-23$ \\
\hline Ascraeus Mons & Amazonian & 70 & 0.7 & 3220 & 0.67 & $120-153$ & $22-30$ & $18-23$ \\
\hline Pavonis Mons & Amazonian & 75 & 1.0 & 3540 & 0.68 & $94-125$ & $20-25$ & $15-19$ \\
\hline Arsia Mons & Amazonian & 85 & 13.0 & 3630 & 0.63 & $27-45$ & $9-11$ & $6-8$ \\
\hline Alba Patera & Amazonian-Hesperian & 65 & 1.2 & 3070 & 0.51 & $60-81$ & $16-19$ & $12-15$ \\
\hline Elysium rise & Amazonian-Hesperian & 45 & 6.1 & 2900 & 0.53 & $61-74$ & $12-15$ & $9-11$ \\
\hline Solis Planum & Hesperian & 70 & -4.7 & 2540 & 0.42 & $33-40$ & $11-12$ & $6-8$ \\
\hline Hellas S rim & Hesperian-Noachian & 55 & -3.4 & 2850 & 0.36 & $43-60$ & $13-15$ & $7-9$ \\
\hline Hellas W rim & Hesperian-Noachian & 55 & 3.9 & 3750 & 0.77 & $23-29$ & $8-11$ & $5-7$ \\
\hline Hellas Basin & Noachian & 15 & 7.6 & 3030 & 0.36 & $51-59$ & $34-39$ & $25-30$ \\
\hline NE Arabia Terra & Noachian & 50 & 2.4 & 3640 & 0.79 & $25-30$ & $9-12$ & $6-7$ \\
\hline Noachis Terra & Noachian & 65 & 3.1 & 3850 & 0.75 & $18-22$ & $7-10$ & $4-5$ \\
\hline Terra Cimmeria & Noachian & 60 & 4.2 & 4830 & 0.97 & $15-18$ & $6-9$ & $4-5$ \\
\hline
\end{tabular}

Age boundary from Hartmann and Neukum (2001), crust thickness from Neumann et al. (2004), curvature from Ruiz et al. (2006), and heat production elements from Taylor et al. (2006)

Negative curvature indicates the compressional field. Lower value calculated elastic thickness for strain-rate of $10^{-19}\left(\mathrm{~s}^{-1}\right)$, and higher for $10^{-16}\left(\mathrm{~s}^{-1}\right)$

\section{Results and discussion}

Sensitivity of elastic thickness to water in the Martian lithosphere

The relationship between elastic and mechanical lithospheric thicknesses is shown in Fig. 5. In our calculations, a constant thermal gradient was assumed to enable comparison of the results with the model employed by Solomon and Head (1990). The elastic thickness is strongly dependent on the thermal gradient and is well correlated with mechanical thickness, although the elastic thickness is much thinner than the mechanical lithosphere (Fig. 5). Calculations performed under dry conditions are largely consistent with the previous model (Solomon and Head 1990); however, calculations under wet conditions yield a much thinner elastic layer. For a thermal gradient of $6 \mathrm{~K} / \mathrm{km}$, the elastic thickness under wet conditions is $\sim 30 \%$ thinner than that under dry conditions (Fig. 5). If frictional coefficient is reduced by the presence of clay minerals, inferred elastic thickness further decreases under the extremely wet conditions. The effect of water on the Martian lithosphere's elastic thickness has been reported by Grott and Breuer (2008); however, Peierls creep was not considered in their model, and hence the elastic thickness could be overestimated. Our wet mantle rheology assumes a water content of $\sim 1000 \mathrm{ppm} \mathrm{H} / \mathrm{Si}$, which corresponds to near-water saturation at the depth of Moho. However, if water is undersaturated in the mantle (and water content is less than this value), the sensitivity of elastic thickness to water would be less than that calculated using our model. In contrast, water solubility can increase at deeper portion of lithosphere, and if the entire lithosphere is saturated with water, both elastic and mechanical thicknesses would be even thinner. Although our calculations assume a constant thermal gradient, the thermal structure likely varies at each location due to local variations in the abundance of radiogenic elements. Moreover, crustal rheology should be considered if the mechanical lithosphere is comparable to or thinner than the thickness of the crust. In the following sections, we incorporated these effects to calculate more realistic rheological structures and investigate the effect of water on elastic thickness.

\section{Rheological profile and elastic thickness of the Martian lithosphere}

We calculated rheological structures for 13 locations on Mars considering local variations in crustal thickness, abundance of radiogenic elements, and thermal structure (parameters are listed in Table 2). Figure 6 shows calculated rheological profiles for Pavonis Mons, Alba Patera, and NE Arabia Terra under dry and wet conditions (all modeling results are shown in (Additional file 1: Figure S1 and Additional file 2: Figure S2). The stress required to initiate brittle deformation increases with depth due to the pressure dependence of the resistance to deformation, whereas the strength of the plastically deforming region decreases with depth owing to its highly temperature-sensitive rheology. Consequently, the upper parts of lithosphere are controlled by brittle deformation and the lower lithosphere by plastic deformation (Fig. 4). The rheological profiles change rapidly at the crust-mantle boundary due to the difference in flow strengths between plagioclase and olivine. At Pavonis Mons, which was formed during the Amazonian, the transition from brittle to plastic deformation occurred at $\sim 70 \mathrm{~km}$. In 


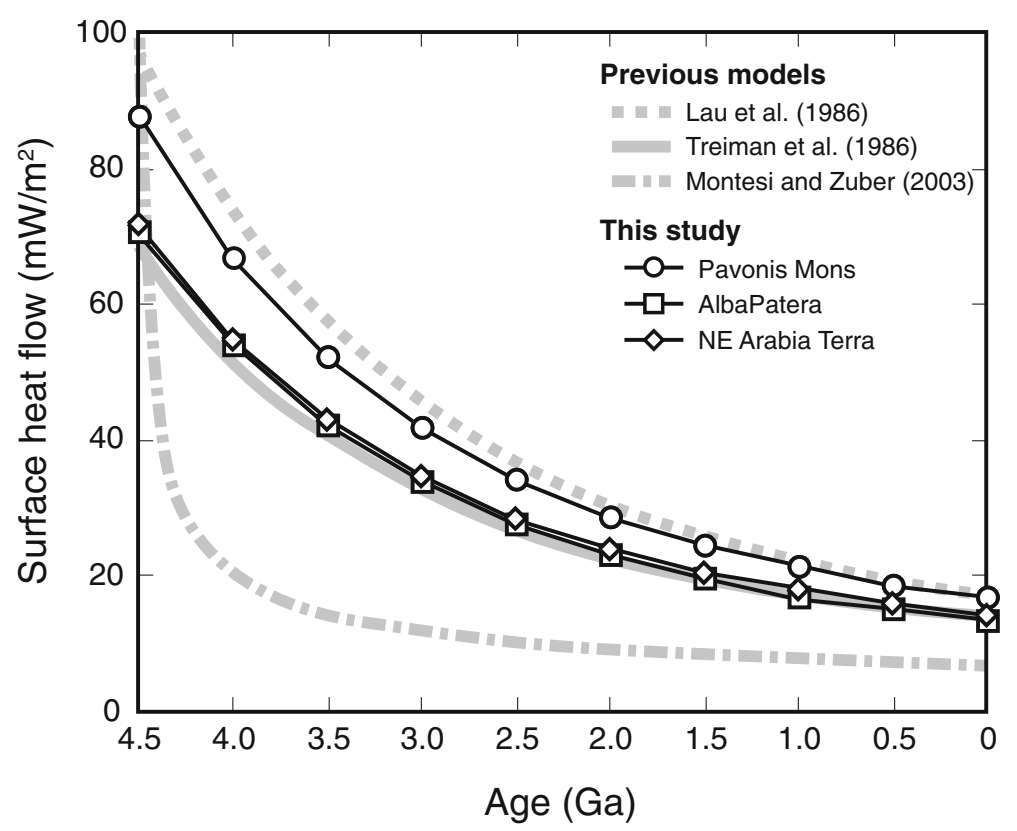

Fig. 3 Calculated surface heat flow at Pavonis Mons, Alba Patera, and NE Arabia Terra during the geological history. The grey lines indicate heat fluxes estimated using different chemical and cooling models (Montesi and Zuber 2003). Nimmo and Tanaka (2005) presented a chemical evolution model, resulted in the averaged surface heat flow of $14.3 \mathrm{~mW} / \mathrm{m}^{2}$ for the present day and $63.4 \mathrm{~mW} / \mathrm{m}^{2}$ for $4.1 \mathrm{Ga}$

contrast, in the older terrains such as NE Arabia Terra during Noachian, the brittle-plastic transition occurred at shallow depths. This temporal change in rheological stratification resulted mainly from cooling of the lithosphere due to the loss of radiogenic elements, which increased its plastic strengths over time. In addition, the presence of water influences both the brittle and plastic strength of the lithosphere; consequently, the brittleplastic transition occurs at shallower depths under wet conditions than under dry conditions (Fig. 3b). This remarkable effect of water on the rheological structure suggests the following investigation into the evolution of water in the Martian interior (Table 3).

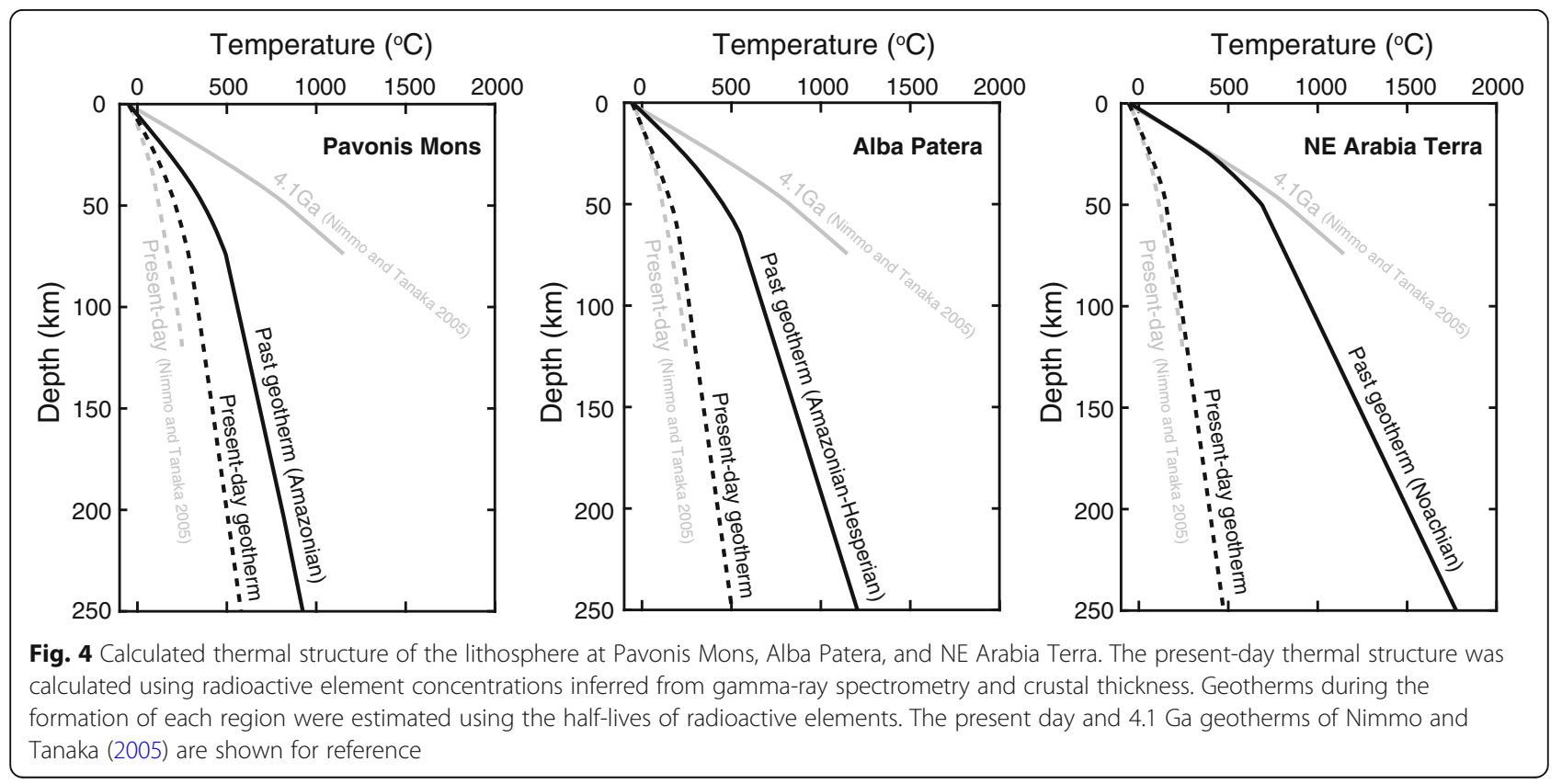




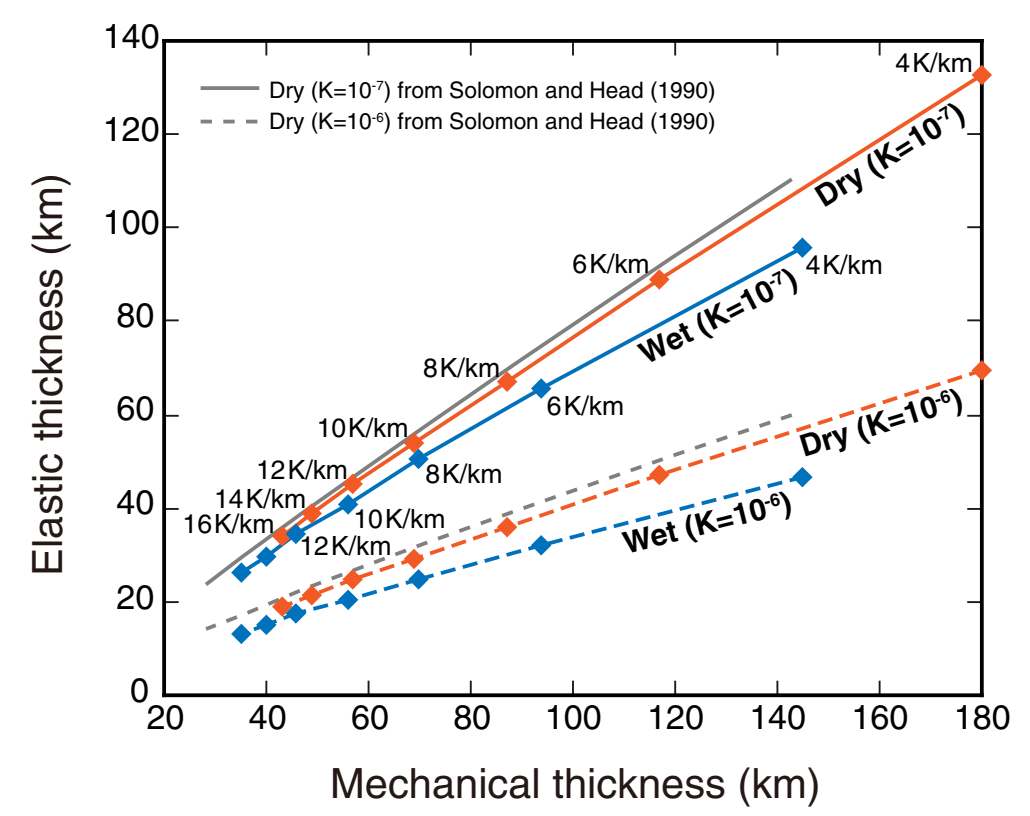

Fig. 5 Relationship between elastic thickness and mechanical thickness. The calculations were made using uniform thermal gradients similar to Solomon and Head (1990). The results for dry mantle rheology agree nearly with their data, but wet rheology gives a markedly thinner elastic and mechanical thicknesses than those for dry rheology at a given thermal gradient. Solid and dashed lines are results using flexural curvature of $10^{-7}$ and $10^{-6} \mathrm{~m}^{-1}$, respectively

Figure 7 shows the calculated elastic thickness at each location for dry and wet conditions. The results indicate a regional variation resulting from difference in crustal thickness and thermal structure, and a general increase in elastic thickness with decreasing age, likely due to secular lithospheric cooling. Our models also show that calculations using a wet rheology produce a significantly thinner elastic layer than those using a dry rheology. Thus, rheological structures and elastic thickness vary in locations due to the variation of radiogenic elements, crustal thickness, geological age, and the presence/absence of water.

Temporal change in elastic thickness and implications for the history of water on Mars

The results of our calculations using dry and wet rheologies are compared with the elastic thickness inferred from gravity and topography data collected by the Mars Global Surveyor (Fig. 7). Observations from Hesperian to Amazonian terrains are generally consistent with a dry rheology. In contrast, the thin elastic layer in the Noachian terrains, including Hellas W rim, NE Arabia Terra, Noachis Terra, and Terra Cimmeria, are consistent with a wet rheology. It should be noted that the calculated thickness for the Hellas basin is much greater than that inferred from observations. This may be due to an extremely thin crust and a low abundance of radioactive elements; however, heat associated with the impact may have enhanced plastic deformation, and therefore our calculation provides an upper estimate. The observed elastic thickness at Ascraeus Mons and Elysium Rise is relatively thin, despite the formation of these terrains during Hesperian to Amazonian, likely due to active mantle upwelling or local influence of water. We did not calculate the elastic thickness at Valles Marineris due to the presence of additional subsurface loads that yield large uncertainties.

Grott and Breuer (2008) used a power-law creep to model the Martian lithosphere with an energy balance thermal equation, and they reached a similar conclusion of wet crust and possible wet mantle to explain the observed elastic thickness during the early evolution. This is most likely due to, particularly at higher temperature, the power-law creep becoming the dominant mechanism controlling the plastic strength, although Peierls creep becomes important as temperature decrease during the evolution. Thermomechanical coupling models by Guest and Smrekar (2007) have shown a lower crustal viscosity $10^{20}-10^{21} \mathrm{~Pa} \mathrm{~s}$ in Noachian, suggesting either wet cold crust or dry hot crust as well as subsequent drying crust to account the admittance elastic thickness in the later stage. The relatively low crustal viscosity is consistent with our water-rich model during the early history of Mars, while increased viscosity due to depletion of volatile results in thick elastic lithospheric thickness during the Hesperian to Amazonian. The present-day dry mantle rheology is also suggested from the recent Monte Carlo simulation by Thiriet et al. (2018). Their 


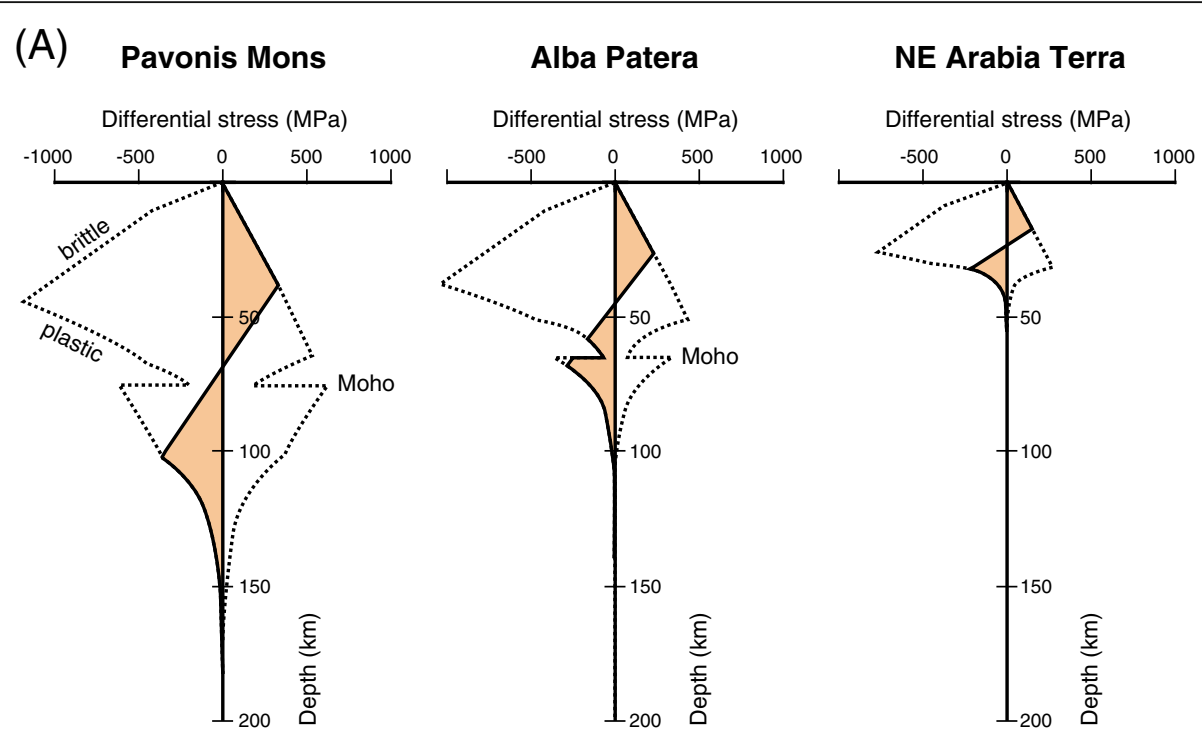

(B)

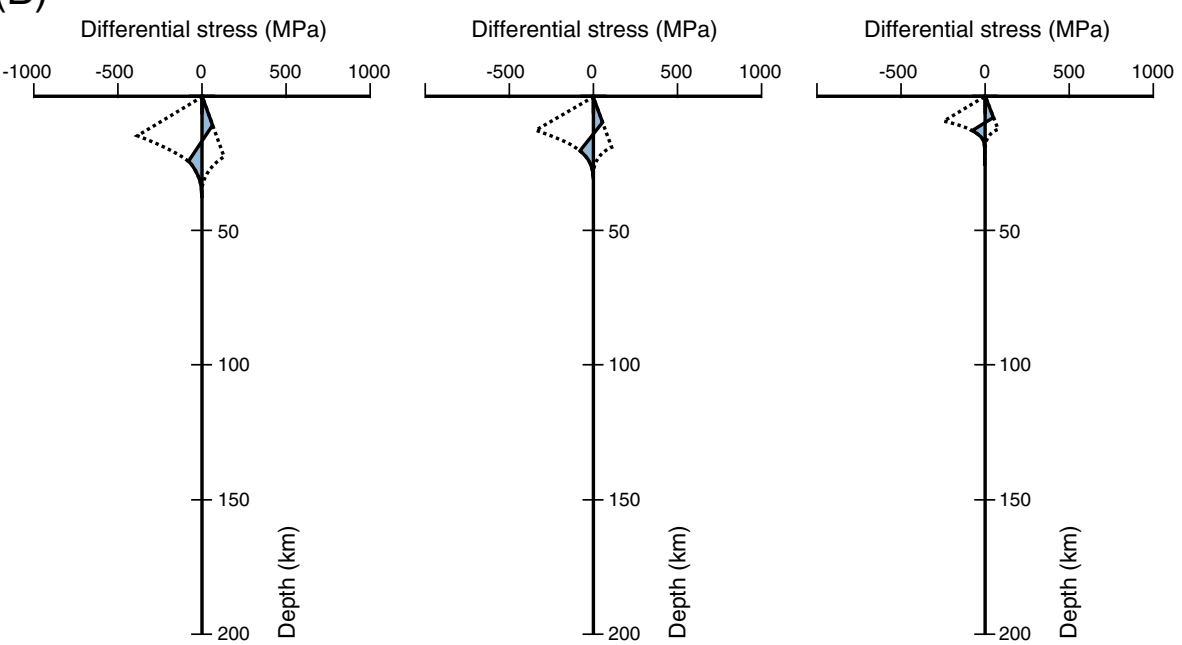

Fig. 6 Rheological structures of the Martian lithosphere at Pavonis Mons, Alba Patera, and NE Arabia Terra calculated under dry (a) and wet (b) conditions. The plastic strength changes across the crust-mantle boundary (Moho) due to a change in flow laws. Elastic thickness was calculated from the integrated bending moment within the lithosphere (see text for details)

models predicted the hemispheric dichotomy in elastic lithosphere caused by the differences in crustal properties and composition.

Given the sensitivity of elastic thickness to water, we suggest that the temporal change in elastic thickness can be explained by a transition from a wet to a dry rheology in the lithosphere. Geochemical analysis of Martian meteorites has produced a wide range of water concentrations, and has implicated hydrous magmatism in the generation of shergottites (McCubbin et al. 2010) and identified subsurface water/ice reservoirs using hydrogen isotopes (Usui et al. 2015); however, these data cannot be used to assess spatial variations in the distribution of water within Mars. Visible/near-infrared orbital images from the Mars Express and Mars Reconnaissance Orbiter spacecraft have indicated the regional occurrence of clay minerals mostly within the Noachian terrains (Ehlmann et al. 2011). Although these clay minerals are formed through near-surface water-rock interaction, they occur in the regions characterized by a water-rich lithosphere, as inferred from our modeling results. The strength of faults associated with bounding rifts suggests the existence of subsurface water during the Noachian, in contrast to dry stronger faults that were active during later periods (Barnett and Nimmo 2002). However, the fault weakening can also occur by dynamic friction even under dry condition at such active zones (e.g., Karato and Barbot 2018). 
Table 3 Flow law parameters

\begin{tabular}{|c|c|c|c|c|c|c|c|}
\hline Rock type & Creep mechanism & $\mathrm{A}\left(\mathrm{s}^{-1} \mathrm{MPa}^{-\mathrm{n}} \mu \mathrm{m}^{\mathrm{m}}\right)$ & $\mathrm{n}$ & $\mathrm{m}$ & $\sigma_{p}(\mathrm{MPa})$ & $\mathrm{E}(\mathrm{kJ} / \mathrm{mol})$ & $V\left(\mathrm{~cm}^{3} / \mathrm{mol}\right)$ \\
\hline \multirow[t]{3}{*}{ Plagioclase (wet) } & Diffusion creep ${ }^{a}$ & $10^{1.7}$ & 1 & 3 & - & 170 & - \\
\hline & Dislocation creep ${ }^{b}$ & $10^{-5.6}$ & 4 & - & - & 235 & - \\
\hline & Peierls creep ${ }^{c}$ & $10^{-1.2}$ & 2 & - & 3410 & 235 & - \\
\hline \multirow[t]{3}{*}{ Plagioclase (dry) } & Diffusion creep ${ }^{a}$ & $10^{12.1}$ & 1 & 3 & - & 467 & - \\
\hline & Dislocation creep ${ }^{b}$ & $10^{0.9}$ & 3.9 & - & - & 431 & - \\
\hline & Peierls creep ${ }^{c}$ & $10^{3.5}$ & 2 & - & 9830 & 431 & - \\
\hline \multirow[t]{3}{*}{ Olivine (wet) } & Diffusion creep ${ }^{d}$ & $10^{9.0}$ & 1 & 3 & - & 335 & 5 \\
\hline & Dislocation creep ${ }^{\mathrm{e}}$ & $10^{4.2}$ & 3 & - & - & 410 & 14 \\
\hline & Peierls creep ${ }^{f}$ & $10^{4.3}$ & 2 & - & 2870 & 410 & 14 \\
\hline \multirow[t]{3}{*}{ Olivine (dry) } & Diffusion creep ${ }^{d}$ & $10^{9.2}$ & 1 & 3 & - & 375 & 4 \\
\hline & Dislocation creep ${ }^{\mathrm{e}}$ & $10^{6.1}$ & 3 & - & - & 510 & 11 \\
\hline & Peierls creep ${ }^{f}$ & $10^{6.3}$ & 2 & - & 9600 & 510 & 11 \\
\hline
\end{tabular}

Wet rheology is assumed to be water-saturated at the condition close to Moho, where water content in olivine is approximately $1000 \mathrm{ppm} \mathrm{H} / \mathrm{Si}$

${ }^{\mathrm{a}}$ Rybacki and Dresen (2000)

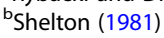

${ }^{\mathrm{c} A z u m a}$ et al. (2014)

dHirth and Kohlstedt (2003)

Earato and Jung (2003)

fKatayama and Karato (2008)

Plate tectonics may have operated during the early evolution of Mars (e.g., Sleep 1994; Sautter et al. 2015; Dohm et al. 2018), and water may have been transported to deeper levels through the subduction of hydrated plates. During subduction, hydrous components are largely released, resulting in the hydration of the hanging wall mantle and crust. Such trapping of water within the lithosphere would decrease the mass of the global ocean, resulting in the removal of liquid water from the surface of Mars. The decay of heat-producing elements after the first billion years may have resulted in a switch to stagnant lid-type convection, and subsequent volcanism during Hesperian to Amazonian may have resulted in the depletion of water in the lithosphere. Wade et al.

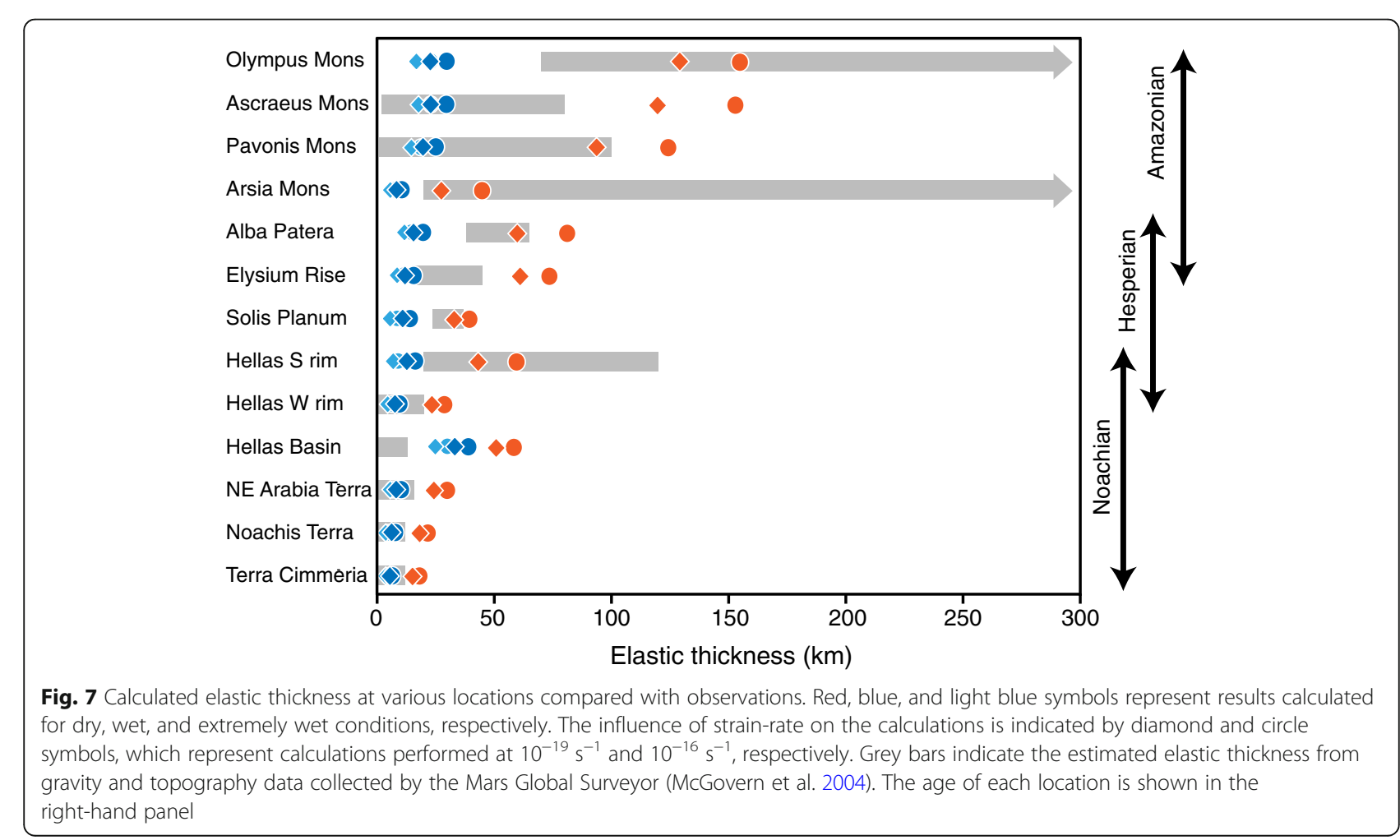


(2017) proposed that that burial and metamorphism of hydrated crustal materials enhanced the downward transport of water within Mars. Volatile elements could also be stored during accretion (e.g., Dreibus and Wänke 1987). Although there are several scenarios to sequester water in Mars, this remains an open question.

\section{Conclusions}

We investigated the sensitivity of elastic thickness to water using recent laboratory data, and found that water weakening effect results in a significantly thinner elastic layer. Gravity and topography data indicate that the elastic thickness of the Martian lithosphere was extremely thin during its early history (prior to $\sim 3.7 \mathrm{Ga}$ ), which can be explained by the presence of water-rich rheological layers. In contrast, a dry rheology can account for the relatively thick elastic layer during the later evolution of Mars. The transition from a water-rich to a dry rheological stratification roughly coincides with the disappearance of oceans that covered the northern plains of Mars, indicating that water was sequestered into a deeper part of the planets. However, we should note the limitation regarding to the thermal evolution that highly influence the estimate of elastic thickness. The proposed model of a water-rich early Martian lithosphere needs to be further tested during the ongoing lander mission (InSight) through systematic heat-flux measurements of Mars.

\section{Additional files}

Additional file 1: Figure S1. Rheological structures at additional locations calculated under dry conditions. Plastic strength was calculated using a strain-rate of $10^{-19} \mathrm{~s}^{-1}$. (PDF $837 \mathrm{~kb}$ )

Additional file 2: Figure S2. Rheological structures at additional locations calculated under wet conditions. Plastic strength was calculated using a strain-rate of $10^{-19} \mathrm{~s}^{-1}$. (PDF $781 \mathrm{~kb}$ )

\section{Acknowledgements}

We thank Tomohiro Usui and Tsuyoshi Komiya for fruitful discussions. Comments from Editors (Shun-ichiro Karato, Yasufumi Iryu) and two anonymous reviewers greatly improved the manuscript. We also thank Victor Baker for comments on an early version of the manuscript.

\section{Authors' contributions}

IK and SA planned the project, and IK and YM conducted the calculations. All authors discussed the results and commented on the manuscript. All authors read and approved the final manuscript.

\section{Funding}

This work was supported by JSPS KAKENHI Grant Number $15 \mathrm{H} 02147$ and 26220713.

\section{Availability of data and materials}

Data sharing not applicable to this article as no datasets were generated or analyzed during the current study. Please contact author for data requests.

\section{Competing interests}

The authors declare that they have no competing interests.

\section{Author details}

'Department of Earth and Planetary Systems Science, Hiroshima University, Higashi-Hiroshima 739-8526, Japan. ${ }^{2}$ Department of Earth and Planetary Sciences, Tokyo Institute of Technology, Meguro 152-8551, Japan.

Received: 15 February 2019 Accepted: 8 July 2019

Published online: 22 July 2019

\section{References}

Azuma S, Katayama I (2017) Evolution of the rheological structure of Mars. Earth, Planets and Space 69:8. https://doi.org/10.1186/s40623-016-0593-z

Azuma S, Katayama I, Nakakuki T (2014) Rheological decoupling at the Moho and implication to Venusian tectonics. Scientific Rep 4:4403. https://doi.org/10.103 8/srep04403

Baker VR, Strom RG, Gulick VC, Kargel JS, Komatsu G, Kale VS (1991) Ancient oceans, ice sheets and the hydrological cycle on Mars. Nature 352:589-594. https://doi.org/10.1038/352589a0

Barlow NG (2008) An introduction to its interior, surface and atmosphere. Cambridge University Press, Cambridge, p 264

Barnett DN, Nimmo F (2002) Strength of faults on Mars from MOLA topography. Icarus 157:34-42. https://doi.org/10.1006/icar.2002.6817

Bürgmann R, Dresen G (2008) Rheology of the lower crust and upper mantle: evidence from rock mechanics, geodesy, and field observations. Annu Rev Earth Planet Sci 36:531-677. https://doi.org/10.1146/annurev.earth.36.0312 07.124326

Byerlee J (1978) Friction of rocks. Pure Appl Geophys 116: 615-626. https://doi. org/10.1007/978-3-0348-7182-2_4.

Carr MH (1986) Water on Mars. Oxford University Press, Oxford, p 248

Carr MH, Head JW (2003) Oceans on Mars: an assessment of the observational evidence and possible fate. J Geophys Res 108:5042. https://doi.org/10.102 9/2002JE001963

Clark SP (1966) Handbook of physical constants. Geol Soc Am Mem 97:587

Di Achille G, Hynek BM (2010) Ancient Ocean on Mars supported by global distribution of deltas and valleys. Nature Geo 3:459-463. https://doi.org/10.1 038/ngeo891

Dohm JM, Maruyama S, Kido M, Baker VR (2018) A possible anorthositic continent of early Mars and the role of planetary size for the inception of Earth-like life. Geoscience Frontiers 9:1085-1098. https://doi.org/10.1016/j. gsf.2016.12.003

Dreibus G, Wänke H (1987) Volatiles on earth and Mars-a comparison. Icarus 71: 225-240. https://doi.org/10.1016/0019-1035(87)90148-5

Ehlmann BL, Mustard JF, Murchie SL, Bibring JP, Meunier A, Fraeman AA, Langevin $Y$ (2011) Subsurface water and clay mineral formation during the early history of Mars. Nature 479:53-60. https://doi.org/10.1038/ nature 10582

Goetze C, Evans B (1979) Stress and temperature in the bending lithosphere as constrained by experimental rock mechanics. Geophys J R 59:463-478. https://doi.org/10.1111/j.1365-246X.1979.tb02567.x

Grott M, Breuer D (2008) The evolution of the Martian elastic lithosphere and implications for crustal and mantle rheology. Icarus 193:503-515. https://doi. org/10.1016/j.icarus.2007.08.015

Gueguen Y, Palciauskas V (1994) Introduction to the physics of rocks. Princeton University Press, Princeton, p 296

Guest A, Smrekar SE (2007) New constraints on the thermal and volatile evolution of Mars. Physics Earth Planet Inter 164:161-176. https://doi.org/10.1 016/j.pepi.2007.06.010

Hartmann WK, Neukum G (2001) Cratering chronology and the evolution of Mars. Space Sci Rev 96:165-194. https://doi.org/10.1007/978-94-017-1035-0_6

Hirauchi K, Fukushima K, Kido M, Muto J, Okamoto A (2016) Reaction-induced rheological weakening enables oceanic plate subduction. Nature Commu 7: 12550. https://doi.org/10.1038/ncomms 12550

Hirth G, Kohlstedt DL (2003) Rheology of the upper mantle and the mantle wedge: a view from the experimentalists. Geophys Monogr 138:83-105. https://doi.org/10.1029/138GM06

Karato S, Barbot S (2018) Dynamics of fault motion and the origin of contrasting tectonic style between earth and Venus. Sci Rep 8. https://doi.org/10.1038/ s41598-018-30174-6

Karato S, Jung H (2003) Effects of pressure on high-temperature dislocation creep in olivine. Phil Mag A 83:401-414. https://doi.org/10.1080/0141861 021000025829 
Katayama I, Karato S (2008) Low-temperature, high-stress deformation of olivine under water-saturated condition. Phys Earth Planet Inter 168:125-133. https://doi.org/10.1016/j.pepi.2008.05.019

Katayama I, Kubo T, Sakuma H, Kawai K (2015) Can clay minerals account for the behavior of non-asperity on the subducting plate interface? Progress in Earth and Planetary Science 2. https://doi.org/10.1186/s40645-015-0063-4

Kieffer HH, Martin TZ, Peterfreund AR, Jakosky BM, Miner ED, Palluconi FD (1977) Thermal and albedo mapping of Mars during the Viking primary mission. J Geophys Res 82:4249-4291. https://doi.org/10.1029/JS082i028p04249

Kohlstedt DL, Evans B, Mackwell SJ (1995) Strength of the lithosphere: constraints imposed by laboratory experiments. J Geophys Res 100:17587-17602. https:// doi.org/10.1029/95JB01460

Laul JC, Smith MR, Wänke H, Jagoutz E, Dreibus G, Palme H, Spettel B, Burghele A, Lipschutz ME, Verkouteren RM (1986) Chemical systematics of the shergotty meteorite and the composition of its parent body (Mars). Geochim Cosmochim Acta 50: 909-926. https://doi.org/10.1016/0016-7037(86)90373-X.

McCubbin FM, Smirnov A, Nekvasil H, Wang J, Hauri E, Lindsley DH (2010) Hydrous magmatism on Mars: a source of water for the surface and subsurface during the Amazonian. Earth Planet Sci Lett 292:132-138. https:// doi.org/10.1016/j.epsl.2010.01.028

McGovern PJ, Solomon SC, Smith DE, Zuber MT, Simons M, Wieczorek MA, Phillips RJ, Neumann GA, Aharonson O, Head JW (2002) Localized gravity/ topography admittance and correlation spectra on Mars: implications for regional and global evolution. J Geophys Res 107:5136. https://doi.org/10.102 9/2002JE001854

McGovern PJ, Solomon SC, Smith DE, Zuber MT, Simons M, Wieczorek MA, Phillips RJ, Neumann GA, Aharonson O, Head JW (2004) Correction to "localized gravity/topography admittance and correlation spectra on Mars: implications for regional and global evolution". J Geophys Res 107:5418. https://doi.org/10.1029/2004JE002286

McNutt MK (1984) Lithospheric flexure and thermal anomalies. J Geophys Res 89: 11180-11194. https://doi.org/10.1029/JB089iB13p11180

Montesi LG, Zuber MT (2003) Clues to the lithospheric structure of Mars from wrinkle ridge sets and localization instability. J Geophys Res 108:5048. https:// doi.org/10.1029/2002JE001974

Morrow CA, Moore DE, Lockner DA (2000) The effect of mineral bond strength and adsorbed water on fault gouge frictional strength. Geophys Res Lett 27: 815-818. https://doi.org/10.1029/1999GL008401

Neumann GA et al (2004) Crustal structure of Mars from gravity and topography. J Geophys Res 109:E08002. https://doi.org/10.1029/2004JE002262

Nimmo F, Stevenson DJ (2000) Influence of early plate tectonics on the thermal evolution and magnetic field of Mars. J Geophys Res 105:11969-11979. https://doi.org/10.1029/1999JE001216

Nimmo F, Tanaka K (2005) Early crustal evolution of Mars. Annu Rev Earth Planet Sci 33:133-161. https://doi.org/10.1146/annurev.earth.33.092203.122637

Plesa A, Grott M, Tosi N, Breuer D, Spohn T, Wieczorek MA (2016) How large are present-day heat flux variations across the surface of Mars. J Geophys Res 121:2386-2403. https://doi.org/10.1002/2016JE005126

Ruiz J, Tejero R, McGovern PJ (2006) Evidence for a differentiated crust in Solis Planum, Mars, from lithospheric strength and heat flow. Icarus 180:308-313. https://doi.org/10.1016/j.icarus.2005.09.010

Rybacki E, Dresen G (2000) Dislocation and diffusion creep of synthetic anorthite aggregates. J Geophys Res 105:26017-26036. https://doi.org/10.1029/2 000JB900223

Sautter V et al (2015) In situ evidence for continental crust on early Mars. Nat Geosci 8:605-609. https://doi.org/10.1038/ngeo2474

Schultz RA (2003) Seismotectonics of the Amethes Rupes thrust fault population, Mars. Geophys Res Lett 30:1303. https://doi.org/10.1029/2002GL016475

Shelton GL (1981) Experimental deformation of single phase and polyphase crustal rocks at high pressures and temperatures. PhD thesis, Brown University

Sleep NH (1994) Martian plate tectonics. J Geophys Res 99:5639-5655. https://doi. org/10.1029/94JE00216

Solomon SC, Head JW (1990) Heterogeneities in the thickness of the elastic lithosphere of Mars: constraints on heat flow and internal dynamics. J Geophys Res 95:11073-11083. https://doi.org/10.1029/JB095iB07p11073

Taylor GJ et al (2006) Bulk composition and early differentiation of Mars. J Geophys Res 111:E03S10. https://doi.org/10.1029/2005JE002645

Tetsuka H, Katayama I, Sakuma H, Tamura K (2018) Effects of humidity and interlayer cations on the frictional strength of montmorillonite. Earth Planet Space 70:56. https://doi.org/10.1186/s40623-018-0829-1
Thiriet M, Michaut C, Breuer D, Plesa A (2018) Hemispheric dichotomy in lithosphere thickness on Mars caused by differences in crustal structure and composition. J Geophys Res 123:823-848. https://doi.org/10.1002/2017JE005431

Treiman AH, Drake MJ, Janssens NJ, Wolf R, Enihara M (1986) Core formation in the Earth and shergottite parent body. Geochim Cosmochim Acta 50: 10611070. https://doi.org/10.1016/0016-7037(86)90389-3.

Tsenn MC, Carter NL (1987) Upper limits of power law creep in rocks. Tectonophysics 136:1-26. https://doi.org/10.1016/0040-1951(87)90332-5

Turcotte DL, Schubert G (2002) Geodynamics. Cambridge Univ. Press, Cambridge, p 456

Usui T, Alexander CM, Wang J, Simon Jl, Jones HH (2015) Meteoritic evidence for a previously unrecognized hydrogen reservoir on Mars. Earth Planet Sci Lett 410:140-151. https://doi.org/10.1016/j.epsl.2014.11.022

Villanueva GL, Mumma MJ, Novak RE, Käufl HU, Hartogh P, Encrenaz T, Tokunaga A, Khayat A, Smith MD (2015) Strong water isotopic anomalies in the martian atmosphere: probing current and ancient reservoirs. Science 348:218-221. https://doi.org/10.1126/science.aaa3630

Wade J, Dyck B, Palin RM, Moore JP, Smye AJ (2017) The divergent fates of primitive hydrospheric water on Earth and Mars. Nature 552:391-394. https:// doi.org/10.1038/nature25031

Zuber MT, Solomon SC, Phillips RJ, Smith DE, Tyler GL, Aharonson O, Balmino G, Banerdt WB, Head JW, Johnson CL, Lemoine FG, McGovern PJ, Neumann GA, Rowlands DD, Zhong S (2000) Global surveyor topography and gravity. Internal structure and early thermal evolution of Mars from Mars. Science 287:1788-1793. https://doi.org/10.1126/science.287.5459.1788

\section{Publisher's Note}

Springer Nature remains neutral with regard to jurisdictional claims in published maps and institutional affiliations.

\section{Submit your manuscript to a SpringerOpen ${ }^{\circ}$ journal and benefit from:}

- Convenient online submission

- Rigorous peer review

- Open access: articles freely available online

- High visibility within the field

- Retaining the copyright to your article

Submit your next manuscript at $\boldsymbol{\nabla}$ springeropen.com 